Article

\title{
Detoxification, Apoptosis, and Immune Transcriptomic Responses of the Gill Tissue of Bay Scallop Following Exposure to the Algicide Thiazolidinedione 49
}

\author{
Cheng Chi ${ }^{1}$, Sib Sankar Giri ${ }^{2}{ }^{\mathbb{D}}$, Jin Woo Jun ${ }^{3}$, Hyoun Joong Kim ${ }^{2}$, Saekil Yun ${ }^{2}$, \\ Sang Wha Kim ${ }^{2}$, Jeong Woo Kang ${ }^{2}$ and Se Chang Park ${ }^{2, *}$ \\ 1 Key Laboratory of Aquatic Nutrition and Feed Science of Jiangsu Province, National Experimental Teaching \\ Center for Animal Science, College of Animal Science and Technology, Nanjing Agricultural University, \\ Weigang Road 1, Nanjing 210095, China \\ 2 Laboratory of Aquatic Biomedicine, College of Veterinary Medicine and Research Institute for Veterinary \\ Science, Seoul National University, Seoul 08826, Korea \\ 3 Department of Aquaculture, Korea National College of Agriculture and Fisheries, Jeonju 54874, Korea \\ * Correspondence: parksec@snu.ac.kr; Tel.: +82-02-880-1282
}

Received: 22 June 2019; Accepted: 23 July 2019; Published: 27 July 2019

check for updates

\begin{abstract}
Thiazolidinedione $49\left(\mathrm{TD}_{49}\right)$, a newly synthesized algicide, shows strong toxicity at low concentrations of 0.1-2.0 $\mu \mathrm{M}$. However, its potential effects on non-target species at the transcript level were not investigated. Differentially expressed genes (DEGs) in the gills of the bay scallop, Argopecten irradians, were accessed after treatment with $0.68 \mu \mathrm{M} \mathrm{TD}_{49}$ for up to $48 \mathrm{~h}$. Following exposure, it was observed that 5214 genes were upregulated and 3497 were downregulated. Functional enrichment analysis revealed that the apoptosis pathway was activated. The extrinsic apoptosis pathway was activated and the survival factors related pathway was suppressed. Furthermore, gene expressions related to ATP-binding cassette, nuclear factor erythroid 2-related factor, B cell lymphoma-2 family protein, glutathione reductase, glutathione peroxidase, catalase, NADPH2:quinone reductase, and superoxide dismutase were decreased. Conversely, gene expressions related to FAS-associated death domain protein, glutathione $S$-transferase, caspase 6, 8, cytochrome P4501A1, and 2C8 were increased. These results comprehensively demonstrated the toxicity of the novel algicide $\mathrm{TD}_{49}$, and should draw the attention of researchers to the importance of analyzing the potential impact of chemical compounds as algicides to control the proliferation of harmful algae, due to the secondary pollution caused by their application.
\end{abstract}

Keywords: algicide; Thiazolidinedione 49; bay scallop; transcriptomic analysis; apoptosis; detoxification; immunity

\section{Introduction}

In the coastal areas of Northeast Asia, especially Japan, South Korea, and China, scallops are a very important commercial species for marine farming, and account for a high proportion of farmed bivalves [1]. Bivalves, including scallops, are often used as indicators of ocean pollution or as model species in various toxicology studies [2,3] due to their filter-feeding habits and their rapid accumulation of pollutants $[4,5]$. In recent decades, rapid increases in agriculture and industrial processes, as well as population booms, have substantially increased the frequency, extent, and inducing factors of red tide globally. This increase in red tides may pose a threat to ecology, the aquaculture industry, and human health [6]. Many physiological and ecological investigations have been performed to reduce the severity 
of losses to coastal fisheries caused by red tides [2,3]. Therefore, developing environmentally friendly algicides has become a major focus of study. In the late 1990s, thiazolidinedione (TD) was developed as an adjunctive therapy for diabetes. TD acts by binding to peroxisome proliferator-activated receptors (PPAR) in the nucleus [6]; it has been shown to be highly effective and selective against harmful algae, with a half maximal inhibitory concentration $\left(\mathrm{IC}_{50}\right)$ in the nanomolar range [7]. The derivative TD $49\left(\mathrm{TD}_{49}\right)$ is a newly synthesized algicide that shows high toxicity at low concentrations of $0.1-2 \mu \mathrm{M}$ against harmful algal species including Cochlodinium polykrikoides, Chattonella marina, and Heterosigma akashiwo [7], as well as very low toxicity to non-harmful algae, even at concentrations of over $100 \mu \mathrm{M}$ [7]. The new International Organization for Standardization (ISO) standard method, which uses algae, crustaceans, and fish as the three representative species for a marine ecological system, is usually employed for acute toxicity assessments [6]. Beak et al. revealed that $0.6 \mu \mathrm{M} \mathrm{TD}_{49}$ treatment had higher biodiversity indices than the high-concentration treatment $(1 \mu \mathrm{M})$, which appeared to show a better algicidal effect with phytoplankton biodiversity enhancement [8], and Zooplankton were not affected by $\mathrm{TD}_{49}$ concentration of $<0.8 \mu \mathrm{M}$ [9]. Moreover, Kim et al. [6] reported that the $\mathrm{LC}_{50}$ of $\mathrm{TD}_{49}$ for Daphnia magna was $0.68 \mu \mathrm{M}$ through an acute toxicity assessment. However, in order to comprehensively assess the algicide activity of $\mathrm{TD}_{49}$, an acute toxicity assessment on the target species is not sufficient. The low toxicity of the algicide for non-target species should not only be less than its acute toxicity to the target species, but also should have no potential irritation to non-target species, especially economically important aquatic animals. Its potential effects on non-target species at the transcriptional level have not yet been addressed. An overall evaluation of the potential effects of $\mathrm{TD}_{49}$ on bivalves is important to effectively establish a method for predicting and evaluating its overall toxicity.

Gene expression profiling is currently widely applied to determine the mechanisms of toxicity induction in chemicals, as well as for predicting their toxicity [1,10-13]. The Illumina HiSeq 4000 sequencing system is used for extensive genome analysis at a relatively low cost and high output to achieve this [14]. Digital gene expression (DGE) analysis based on this sequencing platform has been applied to a growing number of bivalves, such as bay scallop (Argopecten irradians) [13] and Chlamys farreri [15] to investigate their responses to environmental stressors. In a previous study, we used next-generation sequencing for gene profiling of the bay scallop, A. irradians, in response to a novel algicide, palmitoleic acid (PA). The results identified 5414 genes that were significantly upregulated, as well as 4452 genes that were downregulated [12]. Another previous study by this group also investigated differentially expressed genes (DEGs) and transcript abundance in $A$. irradians gill tissue after exposure to okadaic acid using the Illumina HiSeq 400 deep-sequencing platform, and the results showed that 3204 and 2620 genes were significantly upregulated and downregulated, respectively; these genes played roles in cellular processes, immune system processes, metabolic processes, and catalytic process [13].

The aim of the present study was to perform a comprehensive analysis of the molecular toxicological responses of $A$. irradians upon exposure to $\mathrm{TD}_{49}$. The gill is an important respiratory organ in scallops, and acts as a defense barrier owing to its role in the filtration of suspended matter and its high expression of putative immune-related genes [16]. Therefore, the gills were sampled for DGE analysis using the Illumina HiSeq 4000 sequencing system to evaluate whether utilizing $\mathrm{TD}_{49}$ as an algicide poses a potential risk to other marine species.

\section{Materials and Methods}

\subsection{Animal Maintenance and $\mathrm{TD}_{49}$ Exposure}

Bay scallops, A. irradians (average weight: $46.6 \pm 3.9 \mathrm{~g}$; average length: $6-7 \mathrm{~cm}$ ), were purchased from the Zhongcai fisheries wholesale market, Nanjing, China, and maintained in lantern nets suspended in $800 \mathrm{~L}$ tanks with filtered and aerated sea water for 2 weeks to acclimatize them to 
laboratory conditions (temperature: $10 \pm 1{ }^{\circ} \mathrm{C}$; salinity: $30 \% \pm 0.1 \%$ ) before the experiments. Half of the seawater was changed daily before exposure treatment.

For $\mathrm{TD}_{49}$ exposure, the bay scallops were randomly divided into two groups: (1) control group and (2) $\mathrm{TD}_{49}$-exposed group. $\mathrm{TD}_{49}$, which was synthesized according to the methods described by Kim et al. [7], was kindly provided by Professor Hoon Cho, Chosun University (Gwangju, Korea). The $\mathrm{TD}_{49}$ was initially dissolved dimethyl sulfoxide (DMSO) (Sigma, Ronkonkoma, NY, USA) to prepare the $50 \mathrm{mM} \mathrm{TD} 49$ stock solution, and it was ensured that the final concentration of $\mathrm{TD}_{49}$ in the $\mathrm{TD}_{49}$ treatment group as $0.68 \mu \mathrm{M}$ without changing the seawater during the $48 \mathrm{~h} \mathrm{TD} 49$ exposure treatment. The scallops in the $\mathrm{TD}_{49}$-exposed group were exposed to $0.68 \mu \mathrm{M} \mathrm{TD}_{49}$. The control group was exposed with an equal volume of $0.0125 \%$ DMSO in each tank. After exposure to $\mathrm{TD}_{49}$ for up to $48 \mathrm{~h}$, the gills from 18 scallops (six scallops with three replicates each) were sampled and stored in $1 \mathrm{~mL}$ TRIzol reagent (Invitrogen, Carlsbad, CA, USA) at $-80^{\circ} \mathrm{C}$ for RNA extraction. Samples from six scallops were pooled from each replicate for RNA extraction.

\subsection{RNA Preparation}

Total RNA was extracted using TRIzol reagent (Invitrogen, Carlsbad, CA, USA) according to the manufacturer's instructions, and then the purity and rate of degradation of the extracted RNA was measured through $1 \%$ agarose gel electrophoresis. Subsequently, a NanoPhotometer spectrophotometer (Implen, Munich, Germany) and a Qubit RNA Assay Kit with a Qubit 2.0 Fluorometer (Life Technologies, Carlsbad, CA, USA) were used to measure RNA purity and contamination, respectively. Finally, the RNA Nano 6000 Assay Kit with the Agilent Bioanalyzer 2100 system (Agilent Technologies, Santa Clara, CA, USA) was used for RNA integrity analysis.

\subsection{Library Preparation and Illumina Sequencing}

Library preparation and Illumina sequencing were performed by the Beijing Genomics Institute (BGI; Beijing, China). Samples of $200 \mathrm{ng}$ DNase I-treated total RNA were purified using oligo-dT beads. In addition, ribosomal and other non-messenger RNAs were removed. Fragmentation was then induced by fragment buffer to remove poly A-containing mRNAs. First-strand and second-strand cDNA were synthesized by using First Strand Master Mix (Illumina, San Diego, CA, USA) with Super Script II (Invitrogen, Carlsbad, CA, USA), and Second Strand Master Mix (Illumina, San Diego, CA, USA), respectively. Then, the overhangs resulting from fragmentation were converted into blunt ends using End Repair Mix. After adding adenylate 3'-End DNA, the ligation reaction was performed using the RNA Index Adapter and Ligation Mix. Next, PCR Primer Cocktail and PCR Master Mix were added to enrich the cDNA fragments. Afterwards, cDNA fragments (260 bp in length) were selected for PCR amplification. The final library was quantified by quantitative PCR (qPCR) with $1 \mu \mathrm{L}$ of resuspended construct on an Agilent Technologies 2100 Bioanalyzer using Agilent DNA 1000. For cluster generation, the qualified and quantified libraries were first amplified within the flow cell on the cBot instrument (HiSeq 4000 PE Cluster Kit, Illumina, San Diego, CA, USA). For paired-end sequencing, the clustered flow cell was then loaded onto the HiSeq 4000 Sequencer (HiSeq 4000 SBS Kit, Illumina, San Diego, CA, USA) with a recommended read length of $100 \mathrm{bp}$.

\subsection{De Novo Transcriptome Assembly}

Clean data were obtained using SOAPnuke software by removing the reads with adaptors, low-quality reads, and reads in which unknown bases $(\mathrm{N})$ comprised more than $5 \%$ of the reads. Thereafter, the clean reads were assembled using Trinity software to obtain unigenes. The resulting sequences assembled using Trinity were referred to as transcripts. Next, gene family clustering was performed using TIGR Gene Indices clustering tools (TGICL) to obtain the final unigenes. The unigenes were classified into two categories: (1) clusters, labelled with the prefix ' $C L$ ', followed by the cluster ID, and (2) singletons presented with the prefix 'unigene'. 


\subsection{Gene Annotation and Analysis}

BLAST (version: v2.2.23) was used for functional annotation; the unigenes were aligned to the NCBI nucleotide database $(\mathrm{Nt})$, non-redundant protein sequence database $(\mathrm{Nr})$, SwissProt, the Kyoto Encyclopedia of Genes and Genomes (KEGG), and the Clusters of Orthologous Groups (COG) [17]. Moreover, Blast2GO (version: v2.5.0) and InterProScan5 (version: v5.11-51.0) were used to obtain Gene Ontology (GO) annotations in conjunction with the non-redundant protein sequence database $(\mathrm{Nr})$ annotations and InterPro annotations, respectively [18].

\subsection{Enrichment Analysis of DEGs}

In order to map the high-quality reads to the reference unigene sequences, Bowtie (version: 2.2.5) was applied [19]. Calculation of the unigene expression level was performed using RSEM (version: v1.2.12) [20]. DEGs were detected using PossionDis. PossionDis is based on Poisson distribution, and was performed as described by Audic and Claverie [21]. Furthermore, the threshold values applied were false discovery rate (FDR) $<0.001$ and Fold Change $\geq 2.00$ to determine the significance of the DEGs.

DEGs were classified according to the standard classification based on the GO annotation results. $\mathrm{GO}$ and pathway functional enrichment analyses were also processed using phyper, a function of $\mathrm{R}$. $p$-values were calculated using the hypergeometric was as follows:

$$
\mathrm{P}=1-\sum_{\mathrm{i}=0}^{\mathrm{m}-1} \frac{\left(\begin{array}{c}
\mathrm{M} \\
\mathrm{i}
\end{array}\right)\left(\begin{array}{c}
\mathrm{N}-\mathrm{M} \\
\mathrm{n}-\mathrm{i}
\end{array}\right)}{\left(\begin{array}{c}
\mathrm{N} \\
\mathrm{n}
\end{array}\right)}
$$

FDR was used for the correction of each $p$-value. FDR $<0.001$ was defined as significant enrichment.

\subsection{Quantitative Real-Time PCR Verification}

Ten genes related to detoxification, antioxidant ability, and immune responses were selected for the confirmation of DGE data using qPCR. In an initial study, the efficacy of various reference genes (GAPDH, ef1- $\alpha$, and $\beta$-actin) was evaluated following $48 \mathrm{~h}$ exposure to $0.64 \mu \mathrm{M} \mathrm{TD}_{49}$ in scallops. $\beta$-actin was selected as the housekeeping gene after comparing and ranking the candidate reference genes based on the rankings from three algorithms: GeNorm, NormFinder, and BeestKeeper through RefFinder (https://omictools.com/reffinder-tool) [22]. All specific primers used for qPCR are listed in Supplementary File 1. First-strand cDNA was synthesized with 500 ng total RNA using the PrimeScriptTM RT Reagent Kit (TaKaRa Bio, Shiga, Japan). qPCR was performed at $94{ }^{\circ} \mathrm{C}$ for 2 min; followed by 40 cycles at $94^{\circ} \mathrm{C}$ for $20 \mathrm{~s}, 58^{\circ} \mathrm{C}$ for $30 \mathrm{~s}$, and $72{ }^{\circ} \mathrm{C}$ for $40 \mathrm{~s}$ [22], using the QiagenRotor-Gene Q RT-PCR Detection System (Qiagen, Hilden, Germany) in a $12-\mu \mathrm{L}$ reaction volume (1 $\mu \mathrm{L}$ each primer $(10 \mu \mathrm{M}), 6.25 \mu \mathrm{L}$ SYBR Premix (TaKaRa Bio), $1 \mu \mathrm{L}$ cDNA (50 ng), and $2.75 \mu \mathrm{L}$ ultra-pure water). The relative expression of the target genes was calculated according to the method described by Livak and Schmittgen [23]. In all cases, Ct values were determined based on three biological replicates each with two technical replicates.

\subsection{Statistical Analysis}

Statistical analysis was performed using SPSS 19.0 (IBM Corp., Armonk, NY, USA). All data were presented as the mean \pm standard deviation (SD). Significant differences were determined by the least significant difference test. Values of $p<0.05$ were considered statistically significant. 


\section{Results}

\subsection{Analysis of DGE Libraries}

After removing reads with adaptors, reads containing poly-N sequences, and low-quality reads from the raw data, we obtained 9.16 Gb total clean bases, with $45.92 \mathrm{Mb}$ clean reads in both the control and $\mathrm{TD}_{49}$-treated cDNA libraries. The Q20 and GC percentages of clean reads in the two cDNA libraries were $98.21 \%$ and $39.12 \%$ for the control cDNA library, and $98.30 \%$ and $39.23 \%$ for the $\mathrm{TD}_{49}$-exposed cDNA library, respectively (Tables 1 and 2). A total of 78,376 and 71,899 transcripts, with mean sizes of 673 and $632 \mathrm{bp}$ and N50s of 1231 and $1093 \mathrm{bp}$ in the control and TD 49 -exposed groups, were produced using the Trinity tool (Table 2). We thus assumed that the two cDNA libraries were reliable. Finally, transcript sets were further merged with 57,882 unigenes (Table 3). The size distribution of the unigene lengths was as follows: $71.37 \%(21,073)$ of the unigenes had a length of $300-1000 \mathrm{bp} ; 20.88 \%(6165)$ had a length of 1000-3000 bp; and 1.77\% (524) had lengths of greater than 3000 bp, as shown in Figure 1.

Table 1. Summary of sequencing reads after filtering.

\begin{tabular}{ccccccc}
\hline Sample & $\begin{array}{c}\text { Total Raw } \\
\text { Reads } \mathbf{( M b )}\end{array}$ & $\begin{array}{c}\text { Total Clean } \\
\text { Reads } \mathbf{( M b})\end{array}$ & $\begin{array}{c}\text { Total Clean } \\
\text { Bases }(\mathbf{G b})\end{array}$ & $\begin{array}{c}\text { Clean Reads } \\
\text { Q20 (\%) }\end{array}$ & $\begin{array}{c}\text { Clean Reads } \\
\text { Q30 (\%) }\end{array}$ & $\begin{array}{c}\text { Clean Reads } \\
\text { Ratio (\%) }\end{array}$ \\
\hline CN & 45.92 & 45.76 & 4.58 & 98.21 & 95.30 & 99.65 \\
TD & 45.92 & 45.85 & 4.58 & 98.30 & 95.52 & 99.84 \\
\hline
\end{tabular}

Q20: the rate of bases with a quality of greater than 20, CN: control, TD: Thiazolidinedione 49-exposed.

Table 2. Quality metrics of transcripts.

\begin{tabular}{cccccccc}
\hline Sample & Total Number & Total Length & Mean Length & N50 & N70 & N90 & GC (\%) \\
\hline CN & 78,376 & $52,817,747$ & 673 & 1231 & 568 & 252 & 39.12 \\
TD & 71,899 & $45,492,111$ & 632 & 1093 & 518 & 245 & 39.23 \\
\hline
\end{tabular}

N50: a weighted median statistic showing that $\geq 50 \%$ of the total length is contained in the transcripts, GC (\%): the percentage of $\mathrm{G}$ and $\mathrm{C}$ bases in all transcripts, $\mathrm{CN}$ : control, TD: Thiazolidinedione 49-exposed.

Table 3. Quality metrics of unigenes.

\begin{tabular}{cccccccc}
\hline Sample & Total Number & Total Length & Mean Length (bp) & N50 & N70 & N90 & GC (\%) \\
\hline CN & 51,394 & $40,985,988$ & 797 & 1410 & 702 & 302 & 39.48 \\
TD & 48,654 & $36,217,952$ & 744 & 1266 & 637 & 288 & 39.54 \\
All-unigene & 57,882 & $50,329,144$ & 869 & 1594 & 827 & 321 & 39.36 \\
\hline
\end{tabular}

N50: a weighted median statistic indicating that $\geq 50 \%$ of the total length is contained in the unigenes, GC (\%): the percentage of $\mathrm{G}$ and $\mathrm{C}$ bases in all unigenes, CN: control, TD: Thiazolidinedione 49-exposed.

\subsection{Functional Annotation and Species Distribution}

A summary of our functional annotation is shown in Table 4. A total of 28,172 unigenes (accounting for $48.67 \%$ of the total unigenes) were annotated in this way. Of these, 25,267 and 9983 unigenes were annotated to the $\mathrm{Nr}$ and $\mathrm{Nt}$ databases, respectively. There were 19,555 hits via SwissProt, 8729 for COG, 18,931 for KEGG, 4032 for GO, and 19,017 for Interpro (Table 4).

The distribution of Nr-annotated species is shown in Figure 1. A total of 14,712 unigenes were aligned to the COG database (Figure 2). The most frequently identified classes were general function $(20.24 \% ; 2977)$; recombinant and repair related $(8.54 \% ; 1256)$; translation, ribosomal structure, and biogenesis $(8.25 \% ; 1214)$; transcription $(6.44 \% ; 948)$; and posttranslational modification, protein turnover, and chaperones related $(6.27 \% ; 923)$. 
Table 4. Summary of functional annotation of unigenes.

\begin{tabular}{|c|c|c|c|c|c|c|c|c|c|}
\hline Values & Total & $\begin{array}{c}\text { Nr- } \\
\text { Annotated }\end{array}$ & $\begin{array}{c}\text { Nt- } \\
\text { Annotated }\end{array}$ & $\begin{array}{l}\text { SwissProt- } \\
\text { Annotated }\end{array}$ & $\begin{array}{c}\text { KEGG- } \\
\text { Annotated }\end{array}$ & $\begin{array}{c}\text { COG- } \\
\text { Annotated }\end{array}$ & $\begin{array}{l}\text { Interpro- } \\
\text { Annotated }\end{array}$ & $\begin{array}{c}\text { GO- } \\
\text { Annotated }\end{array}$ & Overall \\
\hline Number & 57,882 & 25,267 & 9983 & 19,555 & 18,931 & 8729 & 19,017 & 4032 & 28,172 \\
\hline Percentage & $100 \%$ & $43.65 \%$ & $17.25 \%$ & $33.78 \%$ & $32.71 \%$ & $15.08 \%$ & $32.85 \%$ & $6.97 \%$ & $48.67 \%$ \\
\hline
\end{tabular}




\section{Species Distribution}

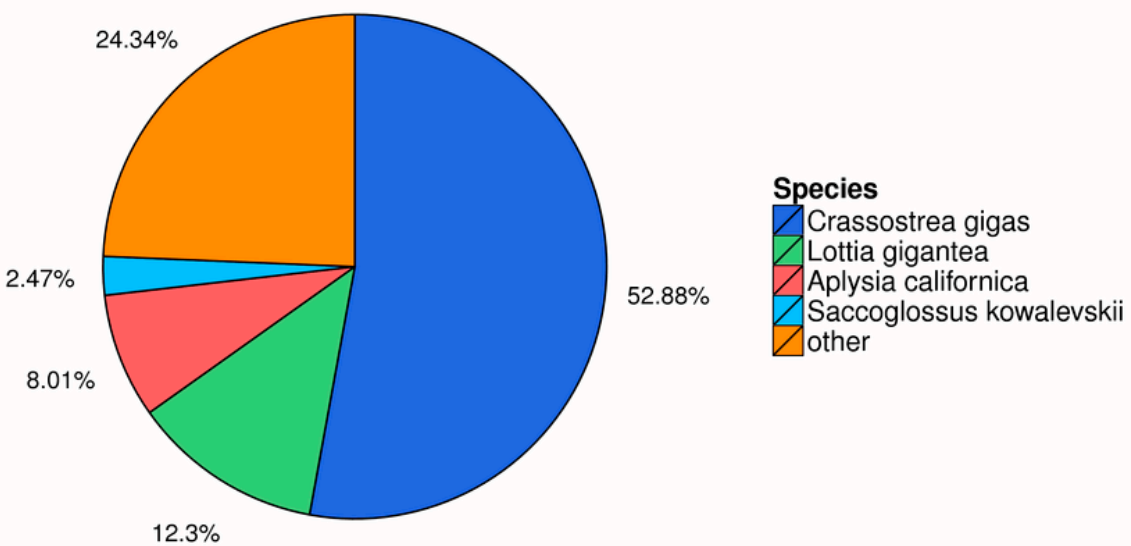

Figure 1. Distribution of annotated species.

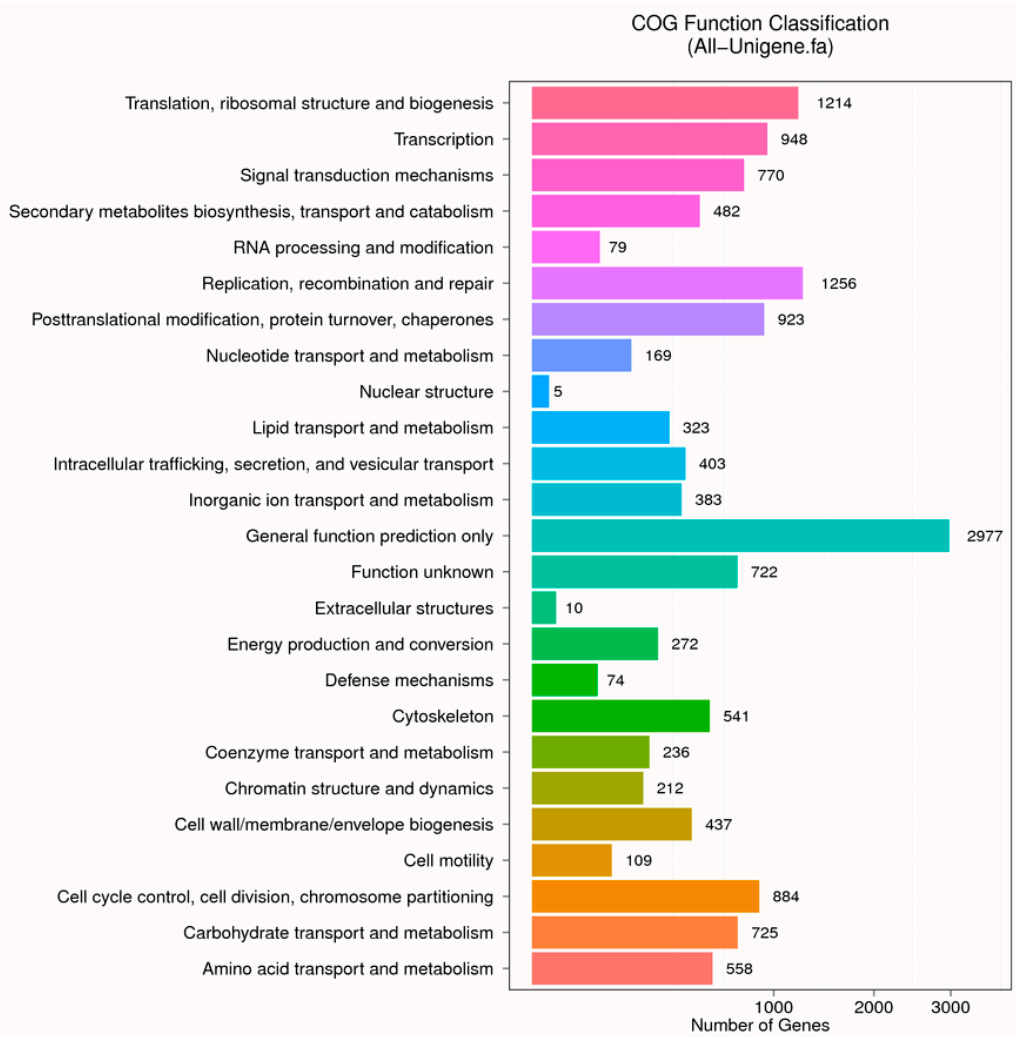

Figure 2. Functional distribution of Clusters of Orthologous Groups (COG) annotation.

\subsection{DEG Analysis}

Differential expression levels between the control and $\mathrm{TD}_{49}$-treated groups are shown in Figures 3 and 4. A total of 8711 unigenes showed differential expression between these two groups (fold change $>2$ and FDR $\leq 0.001$ ); among them, 5214 were identified to be upregulated, while 3497 were downregulated (Supplementary File 2). 


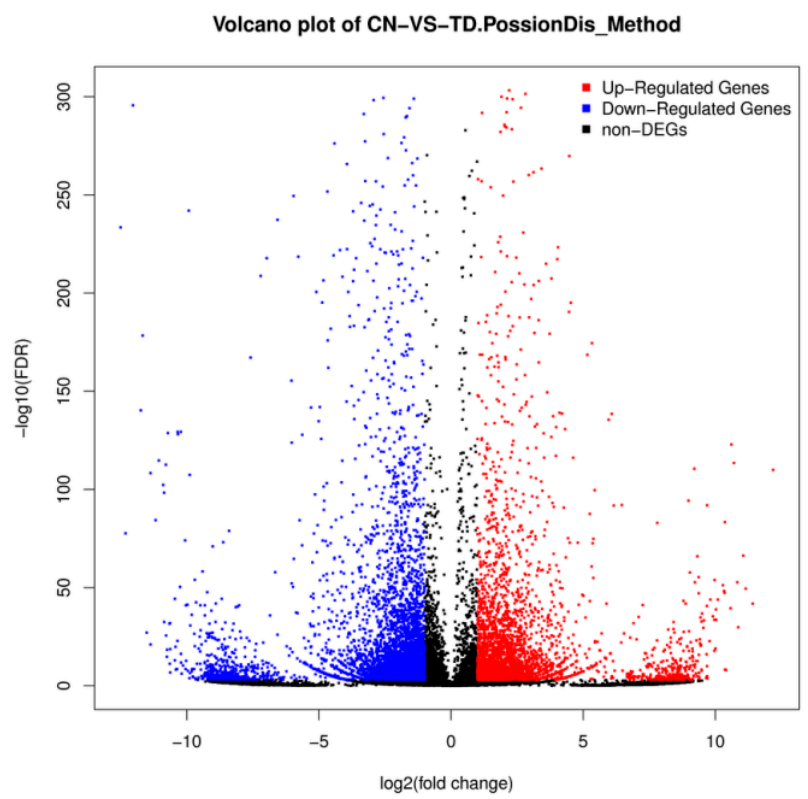

Figure 3. Volcano plot of differentially expressed genes (DEGs) between the control (CN) and Thiazolidinedione (TD)-treated groups.

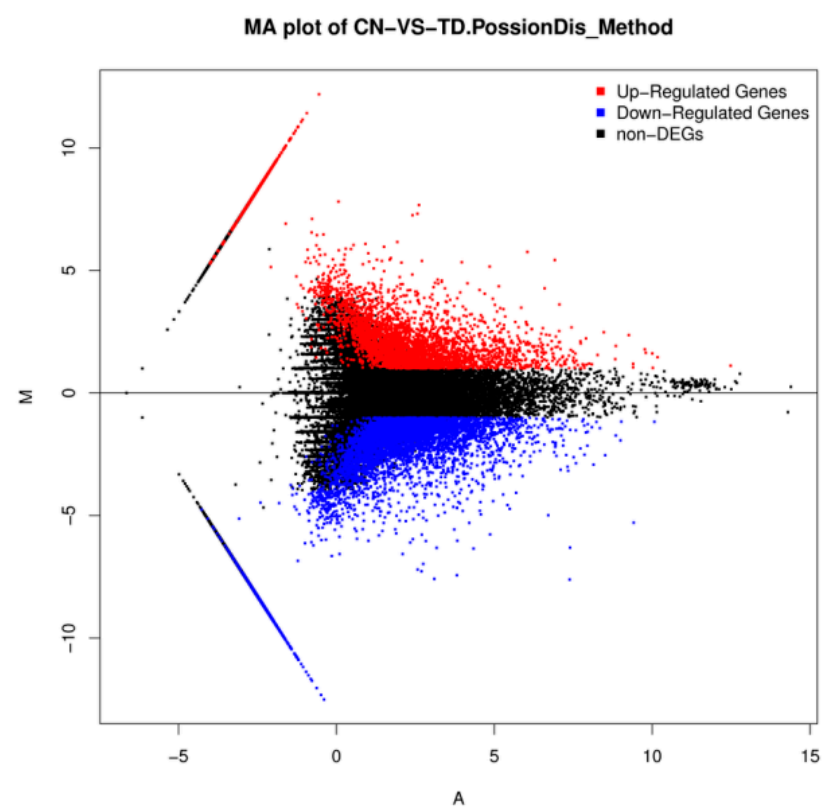

Figure 4. $\mathrm{M}$ (log ratio) and A (mean average) (MA) plot of DEGs between the control $(\mathrm{CN})$ and the Thiazolidinedione (TD)-treated group.

\subsection{Enrichment and Pathway Analysis}

Based on GO annotation, a total of 51 functional groups showed substantial enrichment in DEGs compared to the genomic background (Figure 5). Genes related to the terms 'cellular process', 'metabolic process', 'cell', 'catalytic activity', and 'cell part' were dominant in the TD 49 -exposed scallops. Moreover, the largest percentage of known genes was categorized into biological process and cellular component, followed by molecular function. 


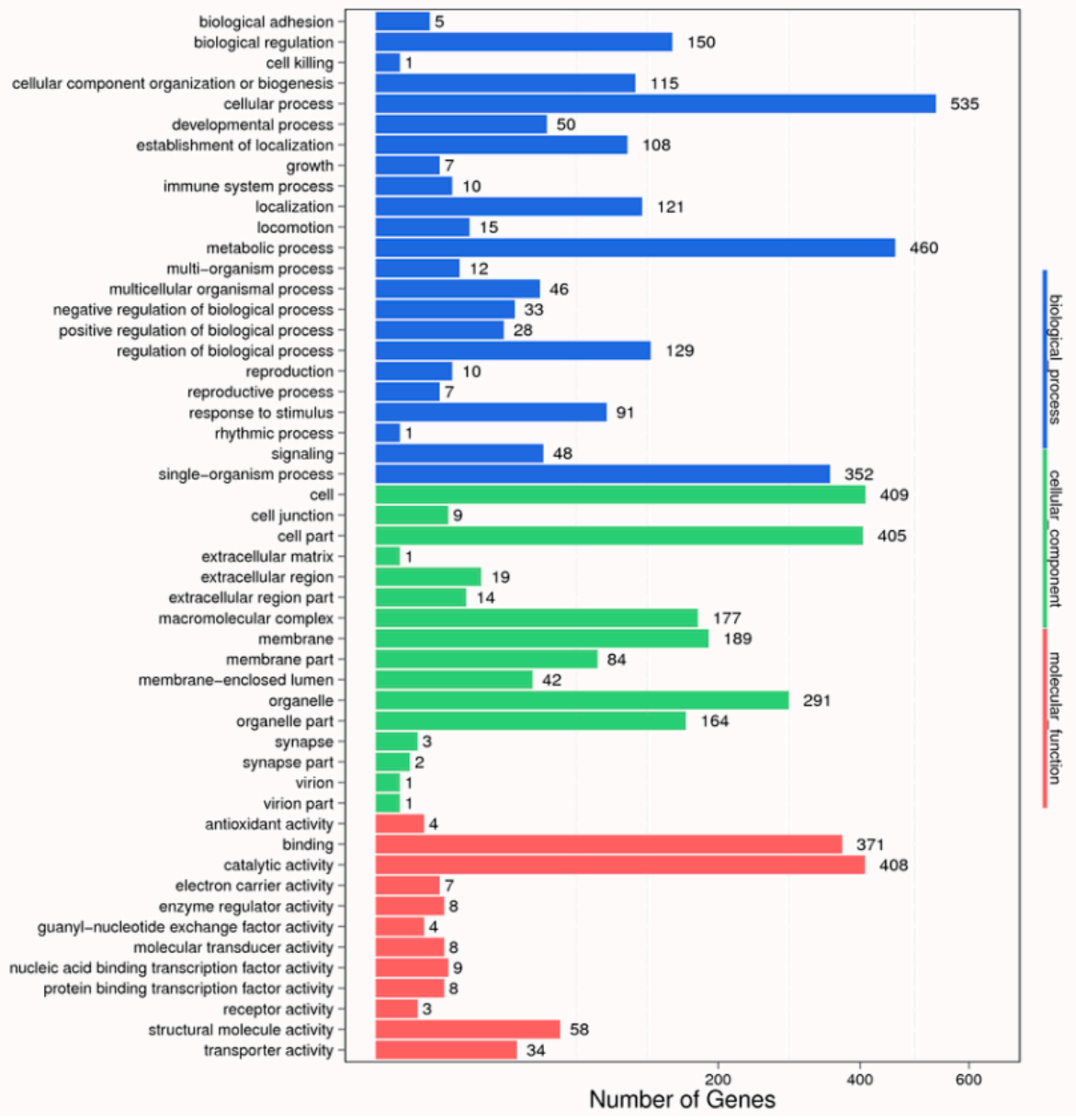

Figure 5. Pathway classification of differentially expressed genes.

KEGG enrichment analysis of the DEGs showed that they were significantly enriched for signal transduction and metabolic pathways; a total of 3076 DEGs were mapped to 302 pathways, and 105 metabolic pathways were over-represented (corrected $p<0.05$ ). Pathway classification and pathway functional enrichment results are shown in Figures 6 and 7, respectively. Among them, 638 genes were annotated to metabolic pathways, 257 to the Rap1 signaling pathway, 208 to the PI3K-Akt signaling pathway, 185 to the Ras signaling pathway, 131 to the mitogen-activated protein kinase (MAPK) signaling pathway, 127 to the cAMP signaling pathway, 86 to the tumor necrosis factor (TNF) signaling pathway, 68 to the nuclear factor-kappa B (NF-KB) signaling pathway, 57 to apoptotic pathways (Figure 8), 50 to the p53 signaling pathway (Figure 9), 44 to the NOD-like receptor signaling pathway, and 42 to the Toll-like receptor (TLR) signaling pathway. The detoxification, apoptosis, and immune-related differentially expressed genes are shown in Table 5. 


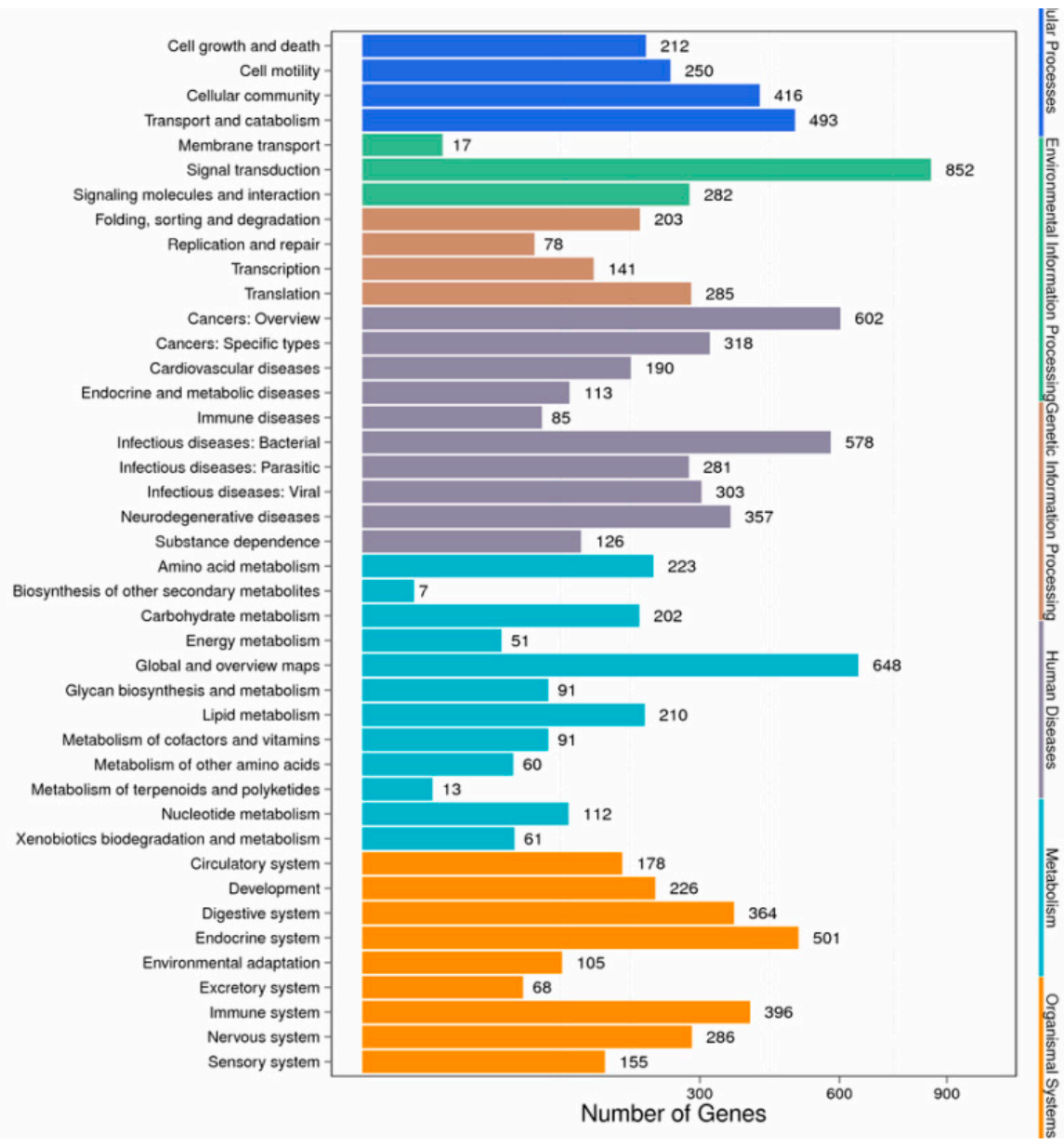

Figure 6. Pathway classification of differentially expressed genes. 


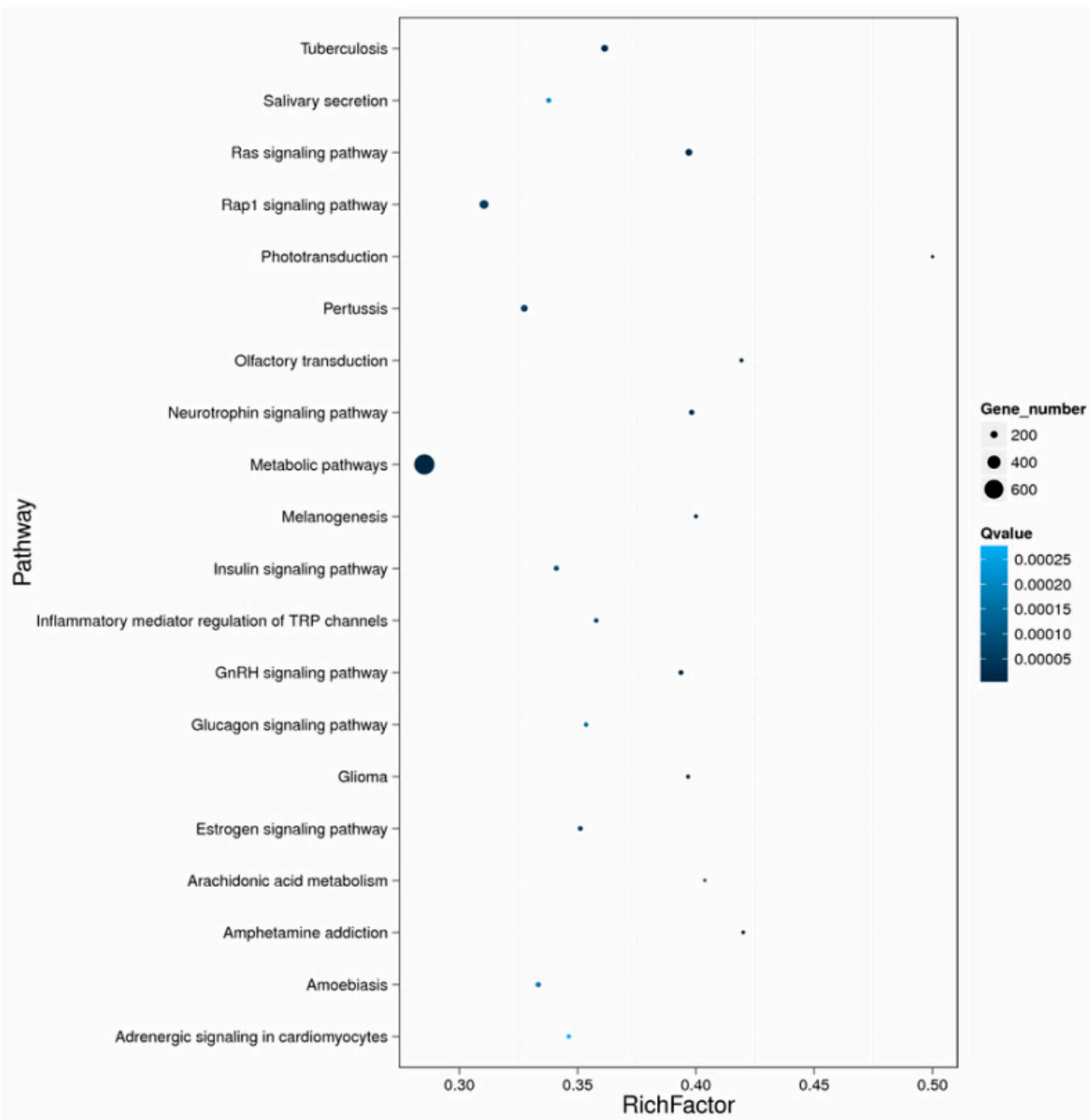

Figure 7. Pathway functional enrichment of differentially expressed genes. Colors indicate q-value (high: white, low: blue), a lower q-value indicates more significantly enriched genes. The size of the dots indicates the degree of differential expression. 


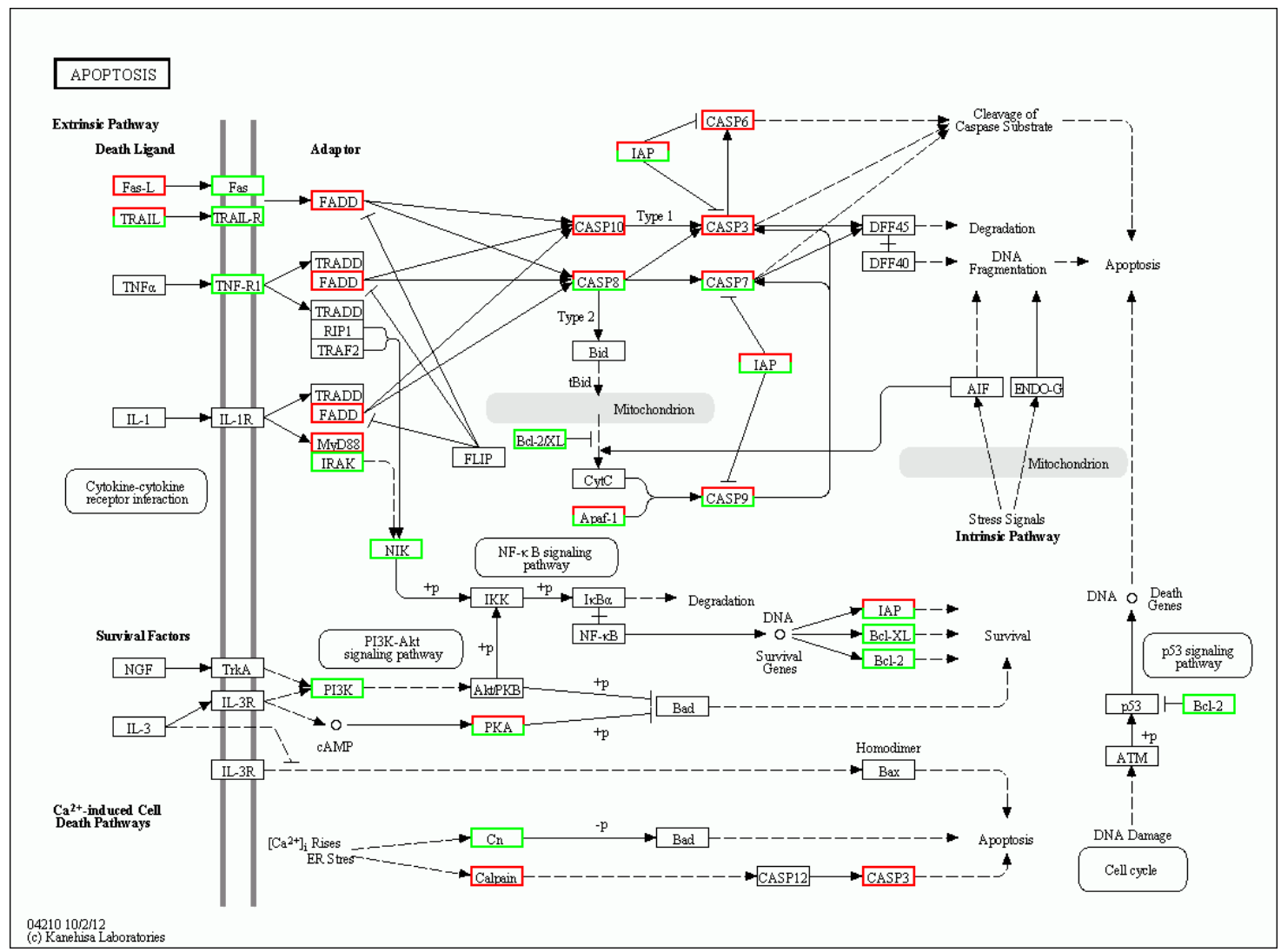

Figure 8. Differentially expressed genes associated with apoptosis pathways. Red, green, and white boxes indicate significantly upregulated, downregulated, and unchanged expression in the transcriptomic profile, respectively.

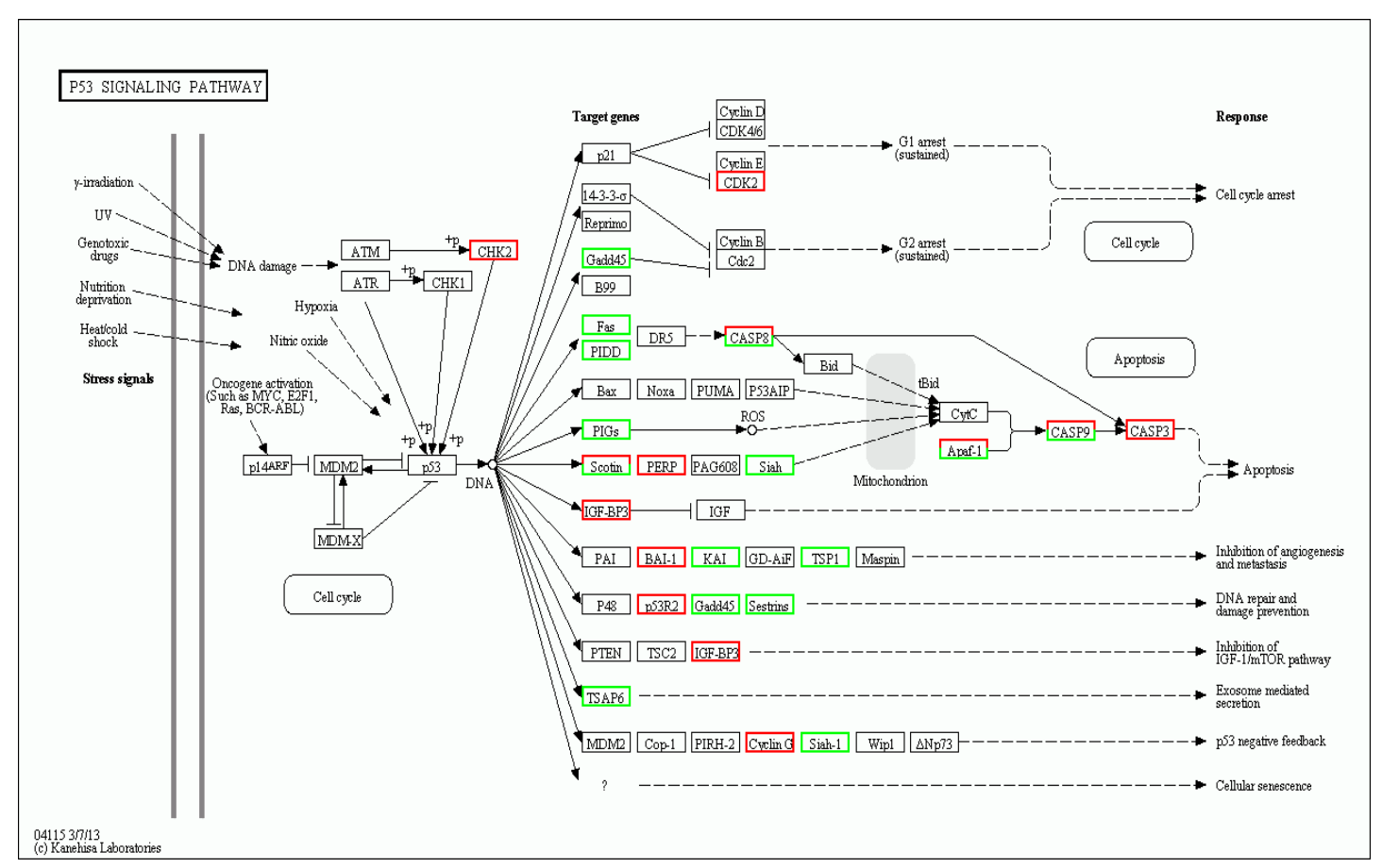

Figure 9. Differentially expressed genes associated with the p53 signaling pathway. Red, green, and white boxes indicate significantly upregulated, downregulated, and unchanged expression in the transcriptomic profile, respectively. 
Table 5. Detoxification, apoptosis, and immune-related differentially expressed genes in gills of bay scallop exposed to Thiazolidinedione $49\left(\mathrm{TD}_{49}\right)$ for up to $48 \mathrm{~h}$.

\begin{tabular}{|c|c|c|c|}
\hline Description & Transcript & Log2 Fold Change (RNAseq) & Regulation \\
\hline \multicolumn{4}{|l|}{ Downregulated } \\
\hline \multirow[t]{7}{*}{ Immune system } & CLEC 4M & -1.62 & Down \\
\hline & CLEC 4F & -2.69 & Down \\
\hline & FIBCD 1 & -2.00 & Down \\
\hline & ACP 5 & -2.94 & Down \\
\hline & ACP 6 & -2.40 & Down \\
\hline & PAPL & -1.27 & Down \\
\hline & HSP70 & -2.00 & Down \\
\hline \multirow[t]{6}{*}{ Apoptosis } & $\mathrm{Bcl}-2$ & -1.90 & Down \\
\hline & BIRC 2 & -2.51 & Down \\
\hline & BIRC 3 & -4.97 & Down \\
\hline & BIRC 6 & -4.25 & Down \\
\hline & BIRC 7A & -1.33 & Down \\
\hline & BIRC 7B & -1.61 & Down \\
\hline \multirow[t]{7}{*}{ Transmembrane proteins } & $\mathrm{ABC} \mathrm{A} 3$ & -5.01 & Down \\
\hline & $\mathrm{ABC}$ A5 & -2.80 & Down \\
\hline & $\mathrm{ABC} B 1$ & -2.11 & Down \\
\hline & $\mathrm{ABC}$ B10 & -4.27 & Down \\
\hline & $\mathrm{ABC} C 1$ & -1.16 & Down \\
\hline & $\mathrm{ABC} D 3$ & -1.32 & Down \\
\hline & $\mathrm{ABC} G 2$ & -1.95 & Down \\
\hline \multirow[t]{7}{*}{ Antioxidant system } & NQO1 & -5.10 & Down \\
\hline & CAT & -3.06 & Down \\
\hline & Mn SOD & -1.30 & Down \\
\hline & $\mathrm{Cu} / \mathrm{Zn} \mathrm{SOD}$ & -1.56 & Down \\
\hline & GR & -5.08 & Down \\
\hline & GPx & -2.55 & Down \\
\hline & Nrf2 & -1.61 & Down \\
\hline \multirow[t]{4}{*}{ Metabolism of xenobiotics } & CREBP 3 & -1.39 & Down \\
\hline & MOA & -1.79 & Down \\
\hline & NOX3 & -1.55 & Down \\
\hline & GST $\omega$ & -11.18 & Down \\
\hline \multicolumn{4}{|l|}{ Upregulated } \\
\hline \multirow[t]{3}{*}{ Apoptosis } & Cas3 & 2.29 & $\mathrm{Up}$ \\
\hline & Cas6 & 2.79 & $\mathrm{Up}$ \\
\hline & FADD & 1.68 & $\mathrm{Up}$ \\
\hline \multirow[t]{2}{*}{ Immune system } & TLR 2 & 4.18 & $\mathrm{Up}$ \\
\hline & TRAF 6 & 1.17 & $\mathrm{Up}$ \\
\hline \multirow[t]{7}{*}{ Metabolism of xenobiotics } & CYP $1 A 1$ & 2.45 & Up \\
\hline & CYP 2C8 & 8.52 & $\mathrm{Up}$ \\
\hline & GST $\zeta 1$ & 8.40 & $\mathrm{Up}$ \\
\hline & GST 1 & 3.08 & $\mathrm{Up}$ \\
\hline & GST $\sigma 3$ & 3.20 & Up \\
\hline & GST A & 3.41 & Up \\
\hline & GST $\kappa 1$ & 1.74 & $\mathrm{Up}$ \\
\hline
\end{tabular}

CLEC: C-type lectin domain family, FIBCD: Fibrinogen C domain-containing protein, TLR: Toll-like receptor, ACP: Lysosomal acid phosphatase, PAPL: Iron/zinc purple acid phosphatase, ABC: ATP-binding cassette sub-family, CAT: Catalase, GR: Glutathione reductase, GST: Glutathione S-transferase, GPx: glutathione peroxidase, Bcl-2: B cell lymphoma-2 family protein, CREBP: Cyclic AMP-responsive element-binding protein, CYP: Cytochrome P450, Nrf2: Nuclear factor erythroid 2-related factor 2, NQO1: NAD(P)H:quinine oxidoreductase 1, NOX3: NADPH oxidase 3, BIRC: Baculoviral IAP repeat-containing protein, FADD: FAS-associated death domain protein, Cas: caspase, TRAF: tumor necrosis factor receptor-associated factor, MOA: flavin-containing monoamine oxidase A, HSP70: Heat shock protein 70, SOD: superoxide dismutase. 


\subsection{Genes Related to $T D_{49}$-Induced Stress Response}

A total of ten transcripts from the DGE libraries were analyzed by qRT-PCR; among them, one was upregulated and nine were downregulated. The detected fold changes from qRT-PCR were compared to those from the DGE analysis results and are shown in Figure 10. The genes exhibited a consistent trend for both qRT-PCR analysis and DGE results. The correlation coefficient between the DGE and qRT-PCR results was $0.96(p<0.001)$.

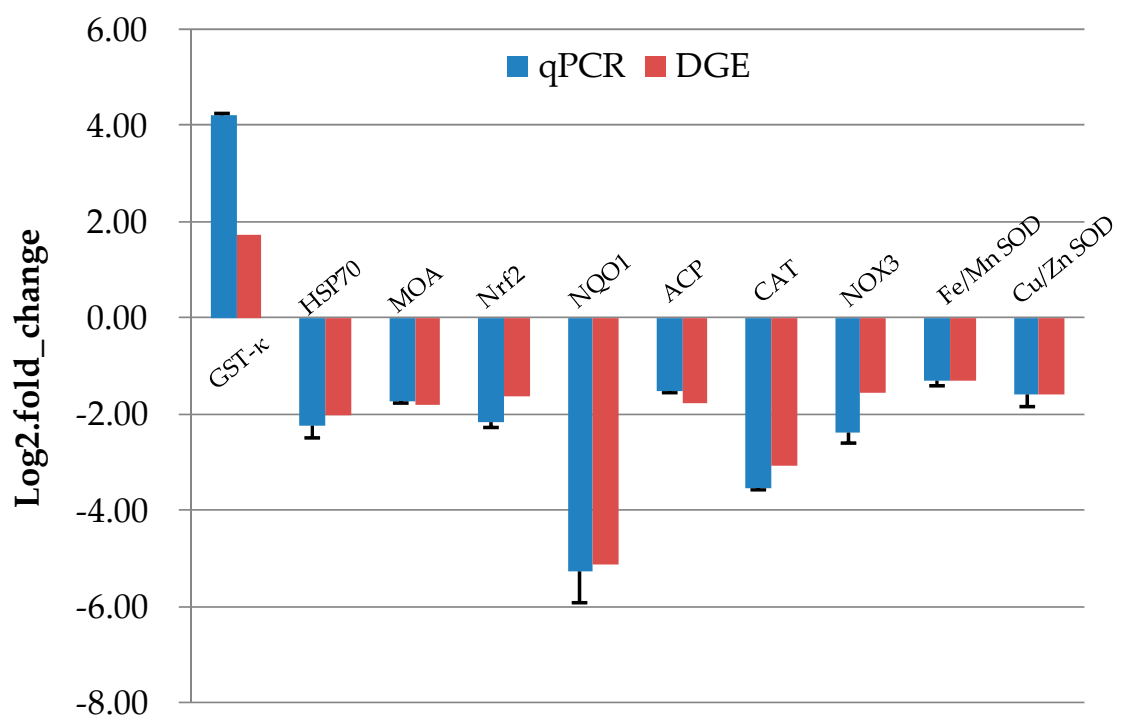

Figure 10. Results of quantitative real time PCR (qPCR) validation (blue) compared to digital gene expression (DGE) analysis results (red). Data represent mean \pm SD values $(n=3)$. GST-Kappa: glutathione-S-transferase Kappa, HSP70: Heat Shock Protein 70, MOA: monoamine oxidase A, Nrf2: Nuclear factor erythroid 2-related factor 2, NQO1: NAD(P)H:quinine oxidoreductase 1, ACP: acid phosphatase, CAT: catalase, NOX3: NADPH oxidase 3, SOD: superoxide dismutase.

\section{Discussion}

For a comprehensive environmental risk assessment, exposure assessment, dose-response assessment, hazard identification, and risk characterization are widely used as standard protocols. $\mathrm{TD}_{49}$ is a newly synthesized algicide that shows high toxicity to harmful algae at low concentrations of $0.1-2 \mu \mathrm{M}$, but shows very low toxicity to non-harmful algae, even at concentrations of $>100 \mu \mathrm{M}$ [7]. However, in the application of $\mathrm{TD}_{49}$ as algicide, $\mathrm{TD}_{49}$ exposure may also cause potential irritation to non-target species, especially for economically important aquatic animals. The current study revealed the overall responses to $\mathrm{TD}_{49}$ exposure by bivalves at the transcript level using transcriptomics analysis, and effectively helped to establish a standard method for predicting and evaluating the toxicity of a novel algicide in bivalves.

Apoptosis is a process of programmed cell death that is characterized by the activation of caspases (Cas), followed by the systematic breakdown of dying cells into vulnerable phagocytized apoptosomes [24]. Members of the antiapoptotic B cell lymphoma-2 family (Bcl-2) including Bcl-XL protects cells from a series of apoptotic factors and are essential for cell survival [25]. In the current study, we found that the expression of Bcl-2 and Bcl-XL was decreased, suggesting that $\mathrm{TD}_{49}$ exposure inhibited the expression of survival factors. In addition, inhibitors of apoptosis (IAP) family proteins, which are characterized by a novel $\sim 70$-amino acid domain known as the baculoviral IAP repeat (BIR), are further important negative regulators of apoptosis [26,27]. In the present study, the expression of baculoviral IAP repeat-containing protein (BIRC)-related genes including BIRC 2, BIRC 3, BIRC 6 , BIRC $7 A$, and BIRC $7 B$ was downregulated, indicating the potential activation of downstream caspase. Meanwhile, elevated Cas3, Cas6, Cas10 and FAS-associated death domain protein (FADD) gene expression levels in the gills of $\mathrm{TD}_{49}$-exposed bay scallops revealed that $\mathrm{TD}_{49}$ induces FADD-dependent 
apoptosis in the gills of bay scallops, thereby inducing apoptosis primarily through the activation of Cas10 and its downstream signaling pathway [28]. Moreover, $\mathrm{TD}_{49}$ exposure also activated apical caspases including Cas8 and Cas9, which then activated the downstream effector Cas3, resulting in cell death.

ATP-binding cassette $(\mathrm{ABC})$ transporters are major transmembrane proteins, and comprise the largest transporter gene family. They play a role in transporting a series of substrates including proteins, sugars, amino acids, peptides, and metal ions, as well as numerous hydrophobic compounds and metabolites across biological membranes [29]. In addition, in aquatic species, they play a part in multiple xenobiotic resistance phenotypes by exporting xenobiotic substances out of the cells or by facilitating the sequestration of toxins within specialized cells or organelles, effectively segregating them from vulnerable protein and DNA targets [12,29]. ABCB1 has been reported to protect cells from toxic factors due to its broad substrate specificity; ABCG2 is similarly involved the transport and efflux of drugs or other toxic compounds [30,31]. ABCC1 was identified as a multidrug resistance gene and has been demonstrated to transport glutathione conjugates originating from many toxic compounds [30]. Therefore, the decreased expression of $A B C B 1, A B C C 1$, and $A B C G 2$ in the gills of bay scallops exposed to $\mathrm{TD}_{49}$ may indicate a reduced ability to resist a wide range of xenotoxins or endogenous stimulants. Previous reports have found that ABCA, ABCG, and ABCD classes act as gatekeepers for the cellular and body homeostasis of sterols, and may exert related functions for the cellular homeostasis of phospholipids and cholesterol and fatty acid metabolism in vertebrates [30]. Hence, the inhibition of $A B C A 3, A B C A 5$, and $A B C D 3$ expression induced metabolic disequilibrium in $\mathrm{TD}_{49}$-exposed bay scallops. Cytochrome P450s (CYP) make up a major family of enzymes which act on many endogenous substrates including fatty acids, eicosanoids, bile acids, sterols and steroids, retinoids, vitamin D3 derivatives, and uroporphyrinogens [32]. NADPH oxidase (NOX), including NOX3, is found in the cytoplasmic membrane of phagocytic cells and can generate reactive oxygen species (ROS) to remove pathogenic invaders [33]. The current results showed that NOX3 mRNA expression was suppressed following $\mathrm{TD}_{49}$ exposure, and it was speculated that the elimination of $\mathrm{TD}_{49}$ was not due to NOX3-mediated ROS production. Moreover, many cytochrome P450 enzymes can metabolize various exogenous compounds including natural plant products, drugs, environmental chemicals, and other contaminants, subsequently resulting in the successful detoxication of the irritant [32]. Among them, CYP 1A1 and CYP 2C8 were identified to be involved in the metabolism of xenobiotics [34]. In our present investigation, the expression of $C Y P 1 A 1$ and $C Y P 2 C 8$ was upregulated, indicating that these proteins activated in response to $\mathrm{TD}_{49}$ invasion. In addition, GSTs represent a major family of

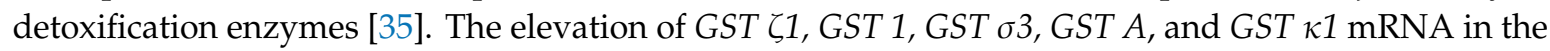
gills of bay scallops after $\mathrm{TD}_{49}$ exposure compared to control implied that the clearing of $\mathrm{TD}_{49}$ was mainly carried out by GST.

The antioxidant defense system functions in the elimination of free radicals and is vital for the response to oxidative stresses and damage. Antioxidant enzymes including catalase (CAT), superoxide dismutase (SOD), glutathione peroxidase (GPx), reductase (GR), and NAD(P)H:quinine oxidoreductase 1 (NQO1) play important roles in detoxification. SOD removes superoxide anions from the cytoplasm by catalyzing the dismutation of two superoxide radicals to hydrogen peroxide $\left(\mathrm{H}_{2} \mathrm{O}_{2}\right)$ and oxygen $\left(\mathrm{O}_{2}\right)$ [36]. Thereafter, $\mathrm{H}_{2} \mathrm{O}_{2}$ is catalyzed by CAT to produce $\mathrm{H}_{2} \mathrm{O}$ and $\mathrm{O}_{2}$ [37]. GPx and GR are also important antioxidative enzymes; when $\mathrm{H}_{2} \mathrm{O}$ toxicity is neutralized by different GPx members, GSH is converted to oxidized glutathione (GSSG), and subsequently reduced by GR, thus maintaining the GSH/GSSG ratio [38]. In the present study, the expression of SOD, CAT, GPX, and GR were inhibited, suggesting that the antioxidant capacity of $\mathrm{TD}_{49}$-exposed bay scallops was strongly inhibited. NQO1 is widely known to have multiple protective functions; it can catalyze the reduction of nitroaromatics, quinoneimines, quinones, and azo dyes compounds, as well as protect cells from redox cycling and oxidative stress $[12,39]$. The present results showed that the expression of NQO1 mRNA in bay scallops decreased after $\mathrm{TD}_{49}$ exposure, indicating that $\mathrm{TD}_{49}$ acted as an inhibitor of NQO1. Therefore, it can be deduced that $\mathrm{TD}_{49}$ exposure may diminish the protective ability of cells against oxidative damage and 
toxic effects, including those caused by quinones. Nrf2 binds to the antioxidant-response element (ARE) and regulates ARE-mediated antioxidant enzyme gene expression in response to a variety of stimuli, including metals, xenobiotics, antioxidants, and UV irradiation [40]. Previous studies demonstrated that Nrf2 can regulate ARE-mediated NQO1 gene expression, and is subsequently involved in the transcriptional activation of other ARE-mediated genes including haem oxygenase 1 (HO-1), the GST $Y a$ subunit, and $\gamma$-glutamylcysteine synthetase $(\gamma$-GCS), proteasomes, and drug transporters [40]. In our current investigation, Nrf2 expression was majorly downregulated, consistent with a previous study showing that PA exposure substantially inhibited the expression of Nrf2 in bay scallops [12]. Hence, we speculated that $\mathrm{TD}_{49}$ suppressed the expression of $N r f 2$, thereby decreasing the expression of downstream antioxidant-related genes including NQO1, SOD, CAT, GPX, and GR [41].

In invertebrates, the innate immune system mainly functions in the prevention of pathogenic invasion, as they lack an acquired immunity. Immune recognition, which discriminates self and non-self, plays a crucial part in initiating the immune response [11]. Immune responses begin when soluble, specialized, or cell-bound pattern recognition receptors (PRRs) recognize pathogen-associated molecular patterns [11,31]. To date, seven distinct PRRs have been identified in scallops, including fibrinogen $C$ domain-containing protein (FIBCD) and C-type lectins (CLEC). In the present study, TLR, CLEC 4M, CLEC 4F, and FIBCD 1 mRNA expression was majorly inhibited after exposure to $\mathrm{TD}_{49}$, indicating that $\mathrm{TD}_{49}$ exposure might suppress the ability of scallops to recognize and clear non-self molecules such as pathogenic bacteria and xenobiotics. The related expression of acid phosphatase $(A C P)$, which is a typical lysosomal enzyme sensitive to environmental stresses [42,43], was reduced in the gills of bay scallops exposed to $\mathrm{TD}_{49}$. This is consistent with a previous study, which reported a decrease in ACP expression in the gills of bay scallops after PA exposure for up to $48 \mathrm{~h}$ [12].

In conclusion, we have comprehensively revealed the transcriptional complexity of the physical responses of bay scallop gills to $\mathrm{TD}_{49}$ exposure, many of which are related to the pathways controlling apoptosis, detoxification, immune response, and antioxidant processes against $\mathrm{TD}_{49}$. Moreover, the current results demonstrated the potential toxicity of the algicide $\mathrm{TD}_{49}$, which might act as an environmental endocrine disruptor for non-target marine species, especially economically important bivalves, since $\mathrm{TD}_{49}$ exposure appeared to activate the apoptosis pathway. Furthermore, the results of this study not only revealed the potential risk of the mainstream application of $\mathrm{TD}_{49}$ as an algicide strategy, but should also draw the attention of researchers to the importance of analyzing the potential impact of chemical compounds as algicides to control the proliferation of harmful algae, due to the secondary pollution caused by their application.

Supplementary Materials: The following are available online at http://www.mdpi.com/2218-273X/9/8/310/s1. Supplementary File 1: The differential expression unigenes between the control and the $\mathrm{TD}_{49}$-treated groups. The accession number for our Raw dataset was submitted to GEO database under the accession number GSE133024.

Author Contributions: C.C. and S.C.P. conceived and designed the experiments; C.C. and S.S.G. performed the experiments; C.C. and J.W.J. analyzed the data; H.J.K., S.W.K., J.W.K., S.Y. contributed with reagents/materials/analysis tools; C.C. wrote the manuscript.

Funding: This work was carried out with the support of "Cooperative Research Program for Agriculture Science and Technology Development (Supportive managing project of Center for Companion Animals Research, PJ013985032018)" Rural Development Administration, Republic of Korea. Natural Science Foundation of China (Grant No.: 31802347).

Acknowledgments: The $\mathrm{TD}_{49}$ was offered by Hoon Cho, Department of Polymer Science and Engineering, Chosun University.

Conflicts of Interest: The authors declare no conflict of interest.

\section{References}

1. Cai, Y.; Pan, L.; Hu, F.; Jin, Q.; Liu, T. Deep sequencing-based transcriptome profiling analysis of Chlamys farreri exposed to benzo pyrene. Gene 2014, 551, 261-270. [CrossRef] [PubMed]

2. Pan, L.; Miao, J.; Wang, J.; Liu, J. AHH activity, tissue dose and DNA damage in different tissues of the scallop Chlamys farreri exposed to benzo pyrene. Environ. Pollut. 2008, 153, 192-198. [CrossRef] [PubMed] 
3. Liu, J.; Pan, L.Q.; Zhang, L.; Miao, J.; Wang, J. Immune responses, ROS generation and the haemocyte damage of scallop Chlamys farreri exposed to Aroclor 1254. Fish Shellfish Immunol. 2009, 26, 422-428. [CrossRef] [PubMed]

4. Goldberg, E.D.; Bowen, V.T.; Farrington, J.W.; Harvey, G.; Martin, J.H.; Parker, P.L.; Risebrough, R.W.; Robertson, W.; Schneider, E.; Gamble, E. The mussel watch. Environ. Conserv. 1978, 5, 101-125. [CrossRef]

5. Liu, N.; Pan, L.; Wang, J.; Yang, H.; Liu, D. Application of the biomarker responses in scallop (Chlamys farreri) to assess metals and PAHs pollution in Jiaozhou Bay, China. Mar. Environ. Res. 2012, 80, 38-45. [CrossRef] [PubMed]

6. Kim, S.J.; Yim, E.C.; Park, I.T.; Kim, S.W.; Cho, H. Comparison of the acute toxicities of novel algicides, thiazolidinedione derivatives TD49 and TD53, to various marine organisms. Environ. Toxicol. Chem. 2011, 30, 2810-2816. [CrossRef] [PubMed]

7. Kim, Y.M.; Wu, Y.; Duong, T.U.; Ghodake, G.S.; Kim, S.W.; Jin, E.; Cho, H. Thiazolidinediones as a novel class of algicides against red tide harmful algal species. Appl. Biochem. Biotechnol. 2010, 162, 2273-2283. [CrossRef] [PubMed]

8. Baek, S.H.; Son, M.; Kim, Y.O.; Cho, H.; Chung, I.K.; Park, B.S. Can algicide (the thiazolidinedione derivative TD49) truly contribute to the restoration of microbial communities? Environ. Res. 2019, 173, 517-527. [CrossRef]

9. Baek, S.H.; Son, M.; Kim, Y.O.; Cho, H.; Lee, M.; Na, D.H.; Kim, S.W. Response of Chattonella marina (Raphidophyceae) and marine plankton to yellow clay and thiazolidinedione derivative TD49 in a mesocosm enclosure. J. Appl. Phycol. 2017, 29, 285-296. [CrossRef]

10. Tian, S.; Pan, L.; Sun, X. An investigation of endocrine disrupting effects and toxic mechanisms modulated by benzo [a] pyrene in female scallop Chlamys farreri. Aquat. Toxicol. 2013, 144, 162-171. [CrossRef]

11. Paules, R.S.; Aubrecht, J.; Corvi, R.; Garthoff, B.; Kleinjans, J.C. Moving forward in human cancer risk assessment. Environ. Health Perspect. 2010, 119, 739-743. [CrossRef] [PubMed]

12. Chi, C.; Giri, S.S.; Jun, J.W.; Kim, H.J.; Kim, S.W.; Kang, J.W.; Park, S.C. Detoxification and immune transcriptomic response of the gill tissue of bay scallop (Argopecten irradians) following exposure to the algicide palmitoleic acid. Biomolecules 2018, 8, 139. [CrossRef] [PubMed]

13. Chi, C.; Giri, S.; Jun, J.; Kim, S.; Kim, H.; Kang, J.; Park, S. Detoxification-and immune-related transcriptomic analysis of gills from bay scallops (Argopecten irradians) in response to algal toxin okadaic acid. Toxins 2018, 10, 308. [CrossRef] [PubMed]

14. Reuter, J.A.; Spacek, D.V.; Snyder, M.P. High-throughput sequencing technologies. Mol. Cell 2015, 58, 586-597. [CrossRef] [PubMed]

15. Fu, X.; Sun, Y.; Wang, J.; Xing, Q.; Zou, J.; Li, R.; Wang, Z.; Wang, S.; Hu, X.; Zhang, L. Sequencing-based gene network analysis provides a core set of gene resource for understanding thermal adaptation in Zhikong scallop Chlamys farreri. Mol. Ecol. Resour. 2014, 14, 184-198. [CrossRef] [PubMed]

16. Philipp, E.E.; Kraemer, L.; Melzner, F.; Poustka, A.J.; Thieme, S.; Findeisen, U.; Schreiber, S.; Rosenstiel, P. Massively parallel RNA sequencing identifies a complex immune gene repertoire in the lophotrochozoan Mytilus Edulis. PLoS ONE 2012, 7, e33091. [CrossRef]

17. Altschul, S.F.; Gish, W.; Miller, W.; Myers, E.W.; Lipman, D.J. Basic local alignment search tool. J. Mol. Biol. 1990, 215, 403-410. [CrossRef]

18. Conesa, A.; Götz, S.; García-Gómez, J.M.; Terol, J.; Talón, M.; Robles, M. Blast2GO: A universal tool for annotation, visualization and analysis in functional genomics research. Bioinformatics 2005, 21, 3674-3676. [CrossRef]

19. Langmead, B.; Salzberg, S.L. Fast gapped-read alignment with Bowtie 2. Nat. Methods 2012, 9, 357-359. [CrossRef]

20. Li, B.; Dewey, C.N. RSEM: Accurate transcript quantification from RNA-Seq data with or without a reference genome. BMC Bioinform. 2011, 12, 323. [CrossRef]

21. Audic, S.; Claverie, J.M. The significance of digital gene expression profiles. Genome Res. 1997, 7, 986-995. [CrossRef] [PubMed]

22. Chi, C.; Giri, S.S.; Jun, J.W.; Kim, H.J.; Kim, S.W.; Yun, S.; Park, S.C. Effects of algal toxin okadaic acid on the non-specific immune and antioxidant response of bay scallop (Argopecten irradians). Fish Shellfish Immunol. 2017, 65, 111-117. [CrossRef] [PubMed] 
23. Livak, K.J.; Schmittgen, T.D. Analysis of relative gene expression data using real-time quantitative PCR and the 2- $\Delta \Delta$ CT method. Methods 2001, 25, 402-408. [CrossRef] [PubMed]

24. Wu, C.C.; Bratton, S.B. Regulation of the intrinsic apoptosis pathway by reactive oxygen species. Antioxid. Redox Signal. 2013, 19, 546-558. [CrossRef] [PubMed]

25. Wong, W.W.L.; Puthalakath, H. Bcl-2 family proteins: The sentinels of the mitochondrial apoptosis pathway. Iubmb Life 2008, 60, 390-397. [CrossRef] [PubMed]

26. Budihardjo, I.; Oliver, H.; Lutter, M.; Luo, X.; Wang, X. Biochemical pathways of caspase activation during apoptosis. Annu. Rev. Cell Dev. Biol. 1999, 15, 269-290. [CrossRef]

27. Deveraux, Q.L.; Reed, J.C. IAP family proteins-suppressors of apoptosis. Genes Dev. 1999, 13, $239-252$. [CrossRef] [PubMed]

28. Park, S.J.; Wu, C.H.; Gordon, J.D.; Zhong, X.; Emami, A.; Safa, A.R. Taxol induces caspase-10-dependent apoptosis. J. Biol. Chem. 2004, 279, 51057-51067. [CrossRef]

29. Huang, L.; Zou, Y.; Weng, H.W.; Li, H.Y.; Liu, J.S.; Yang, W.D. Proteomic profile in Perna viridis after exposed to Prorocentrum lima, a dinoflagellate producing DSP toxins. Environ. Pollut. 2015, 196, 350-357. [CrossRef]

30. Dean, M.; Hamon, Y.; Chimini, G. The human ATP-binding cassette (ABC) transporter superfamily. J. Lipid Res. 2001, 42, 1007-1017. [CrossRef]

31. Schinkel, A.H.; Jonker, J.W. Mammalian drug efflux transporters of the ATP binding cassette (ABC) family: An overview. Adv. Drug Deliv. Rev. 2012, 64, 138-153. [CrossRef]

32. Nebert, D.W.; Russell, D.W. Clinical importance of the cytochromes P450. Lancet 2002, 360, 1155-1162. [CrossRef]

33. Lambeth, J.D. NOX enzymes and the biology of reactive oxygen. Nat. Rev. Immunol. 2004, 4, 181. [CrossRef] [PubMed]

34. Guengerich, F.P. Cytochrome p450 and chemical toxicology. Chem. Res. Toxicol. 2007, 21, 70-83. [CrossRef] [PubMed]

35. Hayes, J.D.; Pulford, D.J. The glut athione S-transferase supergene family: Regulation of GST and the contribution of the lsoenzymes to cancer chemoprotection and drug resistance part I. Crit. Rev. Biochem. Mol. Biol. 1995, 30, 445-520. [CrossRef] [PubMed]

36. Fattman, C.L.; Schaefer, L.M.; Oury, T.D. Extracellular superoxide dismutase in biology and medicine. Free Radic. Biol. Med. 2003, 35, 236-256. [CrossRef]

37. Aebi, H. Catalase in vitro. Methods Enzymol. 1984, 105, 121-126.

38. Bauché, F.; Fouchard, M.H.; Jégou, B. Antioxidant system in rat testicular cells. Febs Lett. 1994, 349, 392-396. [CrossRef]

39. Dinkova-Kostova, A.T.; Talalay, P. NAD (P) H: Quinone acceptor oxidoreductase 1 (NQO1), a multifunctional antioxidant enzyme and exceptionally versatile cytoprotector. Arch. Biochem. Biophys. 2010, 501, 116-123. [CrossRef]

40. Kaspar, J.W.; Niture, S.K.; Jaiswal, A.K. Nrf2: INrf2 (Keap1) signaling in oxidative stress. Free Radic. Biol. Med. 2009, 47, 1304-1309. [CrossRef]

41. Li, H.; Yang, L. Molecular regulatory mechanism of Nrf2 antioxidant. Chin. J. Bioinform. 2018, 16, 1-6.

42. Chen, M.S.; Yang, H.S.; Delaporte, M.; Zhao, S.J.; Xing, K. Immune responses of the scallop Chlamys farreri after air exposure to different temperatures. J. Exp. Mar. Biol. Ecol. 2007, 345, 52-60. [CrossRef]

43. Suresh, K.; Mohandas, A. Hemolymph acid phosphatase activity pattern in copper-stressed bivalves. J. Invertebr. Pathol. 1990, 55, 118-125. [CrossRef]

(C) 2019 by the authors. Licensee MDPI, Basel, Switzerland. This article is an open access article distributed under the terms and conditions of the Creative Commons Attribution (CC BY) license (http://creativecommons.org/licenses/by/4.0/). 